\title{
Ductile behavior of polyethylene fibre reinforced geopolymer composite
}

\author{
Shaikh Faiz Uddin Ahmed ${ }^{1, *}$ and Zammar Ronnie ${ }^{1, \mathrm{~b}}$ \\ ${ }^{1}$ Dept. of Civil Engineering, Curtin University, Australia
}

\begin{abstract}
This paper presents the effects of various volume fractions of polyethylene (PE) fibres of $0.5 \%, 1 \%, 1.5 \%$ and $2 \%$ on tensile, flexure and compressive behavior of PE fibres reinforced geopolymer composites (PEFRGC). Results show that the $1 \%$ PE fibre by volume is the optimum fibre volume fraction for fly ash geopolymer composite, which exhibit superior strain and deflection hardening behavior in uni-axial tension and threepoint bending, respectively. Results also show that the compressive strength of the composites decreases with increase in volume fractions of PE fibre. The fibre surface examination of PE fibre in the gopolymer matrix using scanning electron microscope (SEM) and energy dispersive spectroscopy (EDS) revealed no significant damage of PE fibre in the alkaline geopolymer matrix.
\end{abstract}

\section{Introduction}

Geopolymer binder has been proposed as an alternative to ordinary Portland cement (OPC) binder in concrete and cement based construction materials. It exhibits comparable and even in some instances better mechanical, durability and fire resistance properties than its counterpart OPC binder. As a result real world application of geopolymer can be seen in many projects e.g. precast floor in a library building in University of Queensland, airport runway in Queensland, etc. With continuing research new emerging geopolymer technology will find more real world applications in future.

One of the inherent limitation of OPC concrete or geopolymer concrete is its extremely low tensile strength and crack resistance property. To overcome this limitation short fibres (metallic and polymeric) are added. Significant improvement in tensile strength and crack resistance are obtained in fibre reinforced geopolymer concrete (FRGC). However, the FRGC exhibits ductility after the peak load resulting in increase in crack width due to pullout of fibres or rupturing of fibres during strain softening or deflection softening range. The resulting FRGC material exhibit serious risk in the durability of the structure due to wide crack widths as aggressive chemicals or substances easily penetrates to cause corrosion of steel or deteriorate matrix of the FRGC. Recently, highly ductile strain hardening cement based composites exhibiting multiple fine cracks is developed and as well as its geopolymer based version e.g. [1-3]. The resulting strain hardening geopolymer

\footnotetext{
* Corresponding author: S.Ahmed@curtin.edu.au
} 
composite and deflection hardening geopolymer composite exhibited superior ductility in terms of high tensile strain capacity and deflection at peak load in uni-axial tension and flexure, respectively [2-3]. Steel and polyvinyl alcohol (PVA) fibres are used to reinforced the above ductile geopolymer composites. Steel fibre is considered as high modulus high strength fibre and the PVA fibre is considered as low modulus low strength fibre, which result in high ultimate strength but low ductility and low ultimate strength but high ductility of the composite, respectively. Polyethylene (PE) fibre is another kind of polymeric fibre whose modulus is about twice the PVA and tensile strength is similar to steel fibre. Therefore, by reinforcing geopolymer matrix with PE fibre both high strength and high ductility can be achieved simultaneously. A number of research is reported on the ductility of PE fibre reinforced cement based composites [4-5]. However, no research so far is reported on geopolymer composite containing PE fibres. This paper presents experimental results on ductile behavior of $\mathrm{PF}$ fibre reinforced geopolymer composite containing four different volume fractions of PE fibre ranging from $0.5 \%$ to $2.0 \%$ in uni-axial tension, flexure and uni-xial compression. An optimum volume fraction of PF fibre to achieve the strain hardening and deflection hardening in uni-axial tension and flexure, respectively is also proposed. Microstructure of PF fibre reinforced geopolymer composite is also examined under scanning electron microscope to evaluate the effect of alkali of geopolymer matrix on the PE fibre degradation.

\section{Materials, Mix Proportions, Casting and Testing Details}

The fly ash used is originated from Gladstone power station in Queensland and satisfies ASTM class F classification. The chemical composition of fly ash is shown in Table 1 . The activating solutions used are sodium silicate with a chemical composition of (wt.\%): $\mathrm{Na}_{2} \mathrm{O}$ $=14.7, \mathrm{SiO}_{2}=29.4$ and water $=55.9$. The other characteristics of the sodium silicate solution are specific gravity $=1.53 \mathrm{~g} / \mathrm{cc}$ and viscosity at $20^{\circ} \mathrm{C}=400 \mathrm{cp}$. The sodium hydroxide solution is prepared from analytical grade sodium hydroxide pellets. The mass of the $\mathrm{NaOH}$ solids in the solution varied depending on the concentration of the solution expressed in terms of molar, $\mathrm{M}$. In this study, the $\mathrm{NaOH}$ solution with a concentration of 8 $\mathrm{M}$ is considered and consisted of $8 \times 40=320 \mathrm{~g}$ of $\mathrm{NaOH}$ solids per litre of the solution, where 40 is the molecular weight of $\mathrm{NaOH}$. The sodium hydroxide solution is mixed with $\mathrm{Na}_{2} \mathrm{SiO}_{3}$ (sodium silicate) with the ratio of $0.4: 1$ and produced the alkali activator. The alkali activator solution is then used for the mixing of geopolymer composites.

In this study five series of mixes shown in Table 2 is considered. The first series is the unreinforced geopolymer paste considered as control. While the second to fifth series are geopolymer composites containing $0.5,1.0,1.5$ and $2.0 \% \mathrm{PE}$ fibre, respectively. The mixing is carried out in a Hobart Mixer. First fly ash and alkali activators are mixed for approximately $3 \mathrm{~min}$ and then the PE fibres are slowly added to the wet mix and continued mixing until the fibres are well dispersed in the mix. The geopolymer composite specimens were subjected to oven curing at $85^{\circ} \mathrm{C}$ immediately after casting, for $24 \mathrm{~h}$. The specimens are then demolded after $24 \mathrm{~h}$ and stored in the laboratory in open air until the date of testing. A constant alkali activator to fly ash ratio of 0.4 is considered in all series. The properties of polyethylene (PE) fibre are shown in Table 3.

For each series, three $50 \mathrm{~mm}$ cube specimens for compression, three plate specimens of $15 \times 40 \times 200 \mathrm{~mm}$ in dimension for uni-axial tension and three plate specimens of $15 \times 40 \times 400 \mathrm{~mm}$ in dimension for three-point bending are cast. All specimens are tested after 7 days of curing using a universal testing machine under displacement control with a loading rate of $0.5 \mathrm{~mm} / \mathrm{min}$. 
Table 1. Chemical compositions of class $\mathrm{F}$ fly ash

\begin{tabular}{|l|l|l|l|l|l|l|l|l|l|l|l|l|}
\hline Compounds & $\mathrm{SiO}_{2}$ & $\mathrm{Al}_{2} \mathrm{O}_{3}$ & $\mathrm{Fe}_{2} \mathrm{O}_{3}$ & $\mathrm{CaO}$ & $\mathrm{Na}_{2} \mathrm{O}$ & $\mathrm{K}_{2} \mathrm{O}$ & $\mathrm{MgO}$ & $\mathrm{P}_{2} \mathrm{O}_{5}$ & $\mathrm{SO}_{3}$ & $\mathrm{TiO}_{2}$ & $\mathrm{MnO}$ & $\mathrm{LOI}$ \\
\hline Fly ash & 51.11 & 25.56 & 12.48 & 4.3 & 0.77 & 0.7 & 1.45 & 0.885 & 0.24 & 1.32 & 0.15 & 0.57 \\
\hline
\end{tabular}

Table 2. Mix proportions of geopolymer composites

\begin{tabular}{|c|c|c|c|c|}
\hline \multirow{2}{*}{ Series } & \multirow{2}{*}{$\begin{array}{c}\text { PE fibre (by } \\
\text { Vol.) }\end{array}$} & Fly ash & $\begin{array}{c}\text { Alkali activator/ } \\
\text { fly ash }\end{array}$ & \multirow{2}{*}{$\begin{array}{c}\text { Superplasticizer } \\
\text { (by wt. of fly ash) }\end{array}$} \\
\cline { 3 - 4 } & & 1 & 0.4 & - \\
\hline 1 (Control) & $0 \%$ & 1 & 0.4 & - \\
\hline 2 & $0.5 \%$ & 1 & 0.4 & - \\
\hline 3 & $1.0 \%$ & 1 & 0.4 & $2 \%$ \\
\hline 4 & $1.5 \%$ & 1 & 0.4 & $1 \%$ \\
\hline 5 & $2.0 \%$ & & & \\
\hline
\end{tabular}

Table 3. Properties of Polyethylene (PE) fibre

\begin{tabular}{|c|c|c|c|c|c|c|}
\hline $\begin{array}{c}\text { Type of } \\
\text { Fibre }\end{array}$ & $\begin{array}{c}\text { Length } \\
(\mathrm{mm})\end{array}$ & $\begin{array}{c}\text { Diameter } \\
(\mathrm{mm})\end{array}$ & $\begin{array}{c}\text { Modulus of } \\
\text { elasticity } \\
(\mathrm{MPa})\end{array}$ & $\begin{array}{c}\text { Fibre tensile } \\
\text { Strength } \\
(\mathrm{MPa})\end{array}$ & $\begin{array}{c}\text { Density } \\
\left(\mathrm{gm} / \mathrm{cm}^{3}\right)\end{array}$ & $\begin{array}{c}\text { Elongation } \\
(\%)\end{array}$ \\
\hline Polyethylene & 12 & 0.012 & 73,000 & 2,580 & 0.97 & - \\
\hline
\end{tabular}

\section{Results and Discussions}

The effect of various volume fractions of PE fibre on the compressive behavior of PE fibre reinforced geopolymer composite (PE-FRGC) is shown in Fig. 1. It can be seen that the control mix achieved about $80 \mathrm{MPa}$ and the compressive strength of the composites decreased with increase in volume fractions of $\mathrm{PE}$ fibre. This gradual reduction in compressive strength can be attributed to the formation of entrapped air or pores inside the composite and it increased with increase in volume fractions of fibres. Similar reduction in compressive strength of polypropylene fibres reinforced geopolymer composite is also reported by Zhang et al. [6]. However, unlike the control geopolymer, the PE-FRGC did not exhibit such catastrophic failure. While the cube specimens of PE-FRGC indeed fractured they still maintained their overall shape and it was still possible for some compression force to be applied as evident from the softening tail of the compressive stressaxial strain behavior of various PE-FRGC shown in Fig. 1 and the post-peak axial deformation increases with increase in volume fractions of PE fibres. 


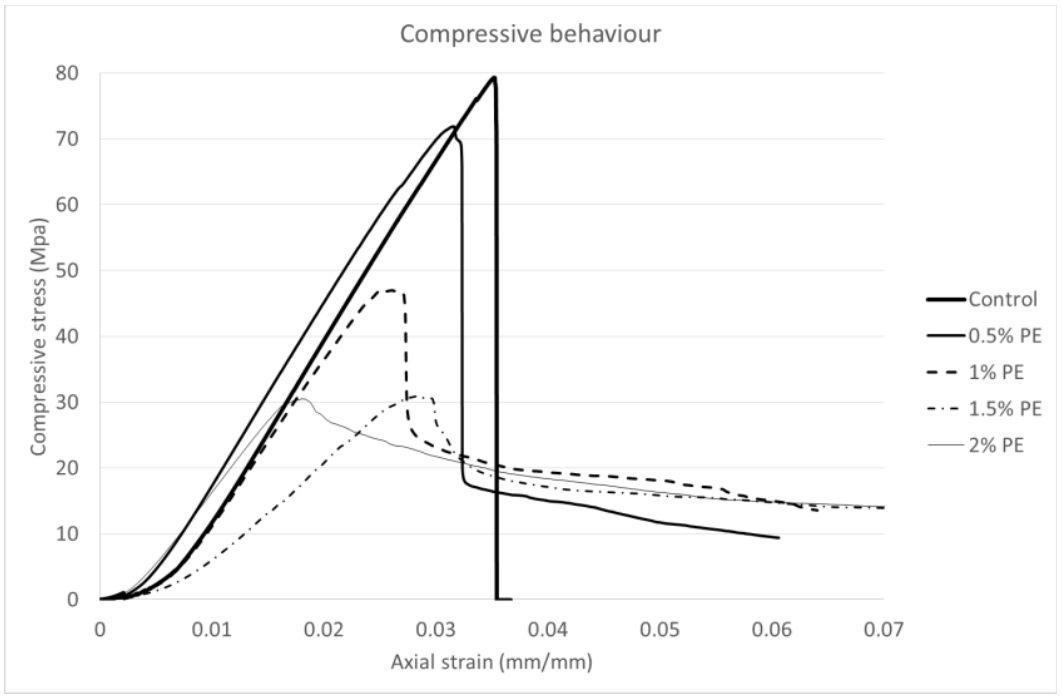

Fig. 1: Compressive stress vs. axial strain behavior of geopolymer composites.

The effects of various volume fractions of PE fibres on the tensile stress-stain behavior of geopolymer composites is shown in Fig. 2. The control specimen failed catastrophically under tension and hence its stress-strain curve was not possible to capture and is not shown in Fig. 2. It can be seen in Fig. 2 that all PE-FRGC exhibited strain hardening and multiple cracking behavior with composite containing $0.5 \%$ and $1 \%$ PE fibres exhibited exceptionally higher strain capacities from $4-5 \%$ at peak load. The number of multiple cracks and their spacing are also higher and lower, respectively compared to composites containing higher volume fractions of PE fibres e.g. at $1.5 \%$ and $2 \%$. This can be attributed to the poor dispersion of $\mathrm{PE}$ fibre at higher volume fractions compared to lower volume fractions. Due to low density of PE fibre there is very likely possibility of formation of fibres balling during mixing which entrapped voids in the composite. These voids believed to be caused the stress concentration and propagated the crack formation as insufficient distributed fibres were present in the vicinity of the voids area.

By comparing with present composite containing 1\% PE fibre, it can be seen that, similar level of strain capacity was achieved in PVA fibre reinforced geopolymer composite at $2 \%$ volume fractions in a PVA fibre reinforced geopolymer composite [2]. However, the ultimate tensile strength in present PE-FRGC containing 1\% PE fibre is slightly lower than that of PVA fibre reinforced geopolymer composite at $2 \%$ volume fractions. The slightly lower tensile strength capacity of PE-FRGC than its PVA counterpart can be attributed to the half the volume fractions of PF fibre in the composite. Nevertheless, with half the volume fraction of fibre the PE-FRGC composite exhibited similar tensile ductility to its PVA fibre counterpart. 

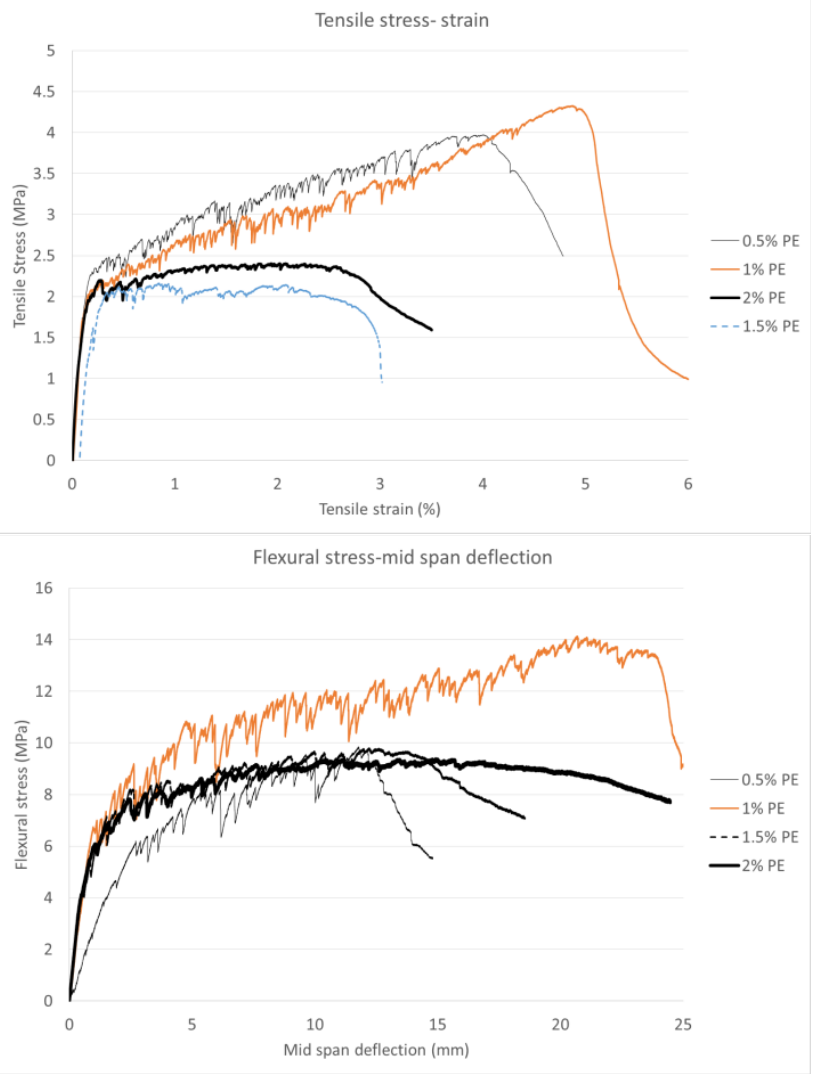

Fig. 2: Tensile strain hardening (left) and deflection hardening (right) behavior of PEFRGC

The deflection hardening behavior of PE-FRGC under three point bending is also shown in Fig. 2. It can be seen in figure that the deflection hardening behavior under three point bending is very similar to the strain hardening behaviour observed in the same composites. The PE-FRGC containing 1\% PE fibre exhibited the highest deflection capacity at peak load and the maximum flexural strength compared to other volume fractions. By increasing the volume fractions of PE fibre to $1.5 \%$ and $2 \%$ resulted in lower deflection capacity and flexural strength and can be attributed to the formation of fibre balling due to non-uniform dispersion of PE fibres at high volume fractions. It can also be seen that the ductility index which is defined as the ratio of deflection at peak load to that at first crack load of PE-FRGC containing 1\% PE fibre is about 22, which is still high but lower than that obtained in the case of $2 \%$ (vol.) PVA fibre reinforced geopolymer composites reported in [3]. The lower ductility index obtained in this study can be attributed to the $50 \%$ more thickness of the flexure specimens, half the volume fraction of PE fibre and the 3-point bending test used in this study.

The effect of alkalinity of geopolymer on the degradation of PE fibre in the composite is also examined through SEM and EDS analysis. Fig. 3 shows the SEM image of individual PE fibre and that in the geopolymer matrix. The SEM image shows that the PE fibre is not damaged by the alkalinity of the geopolymer as evidenced by carbon peak obtained in the EDS analysis (Fig. 3). Fig. 3 also shows the evidence of adherence of geopolymer gel on 
the PE fibre in the composite as indicated by four peaks of $\mathrm{Si}, \mathrm{Na}, \mathrm{O}$ and $\mathrm{Al}$ in $\mathrm{EDS}$ analysis.
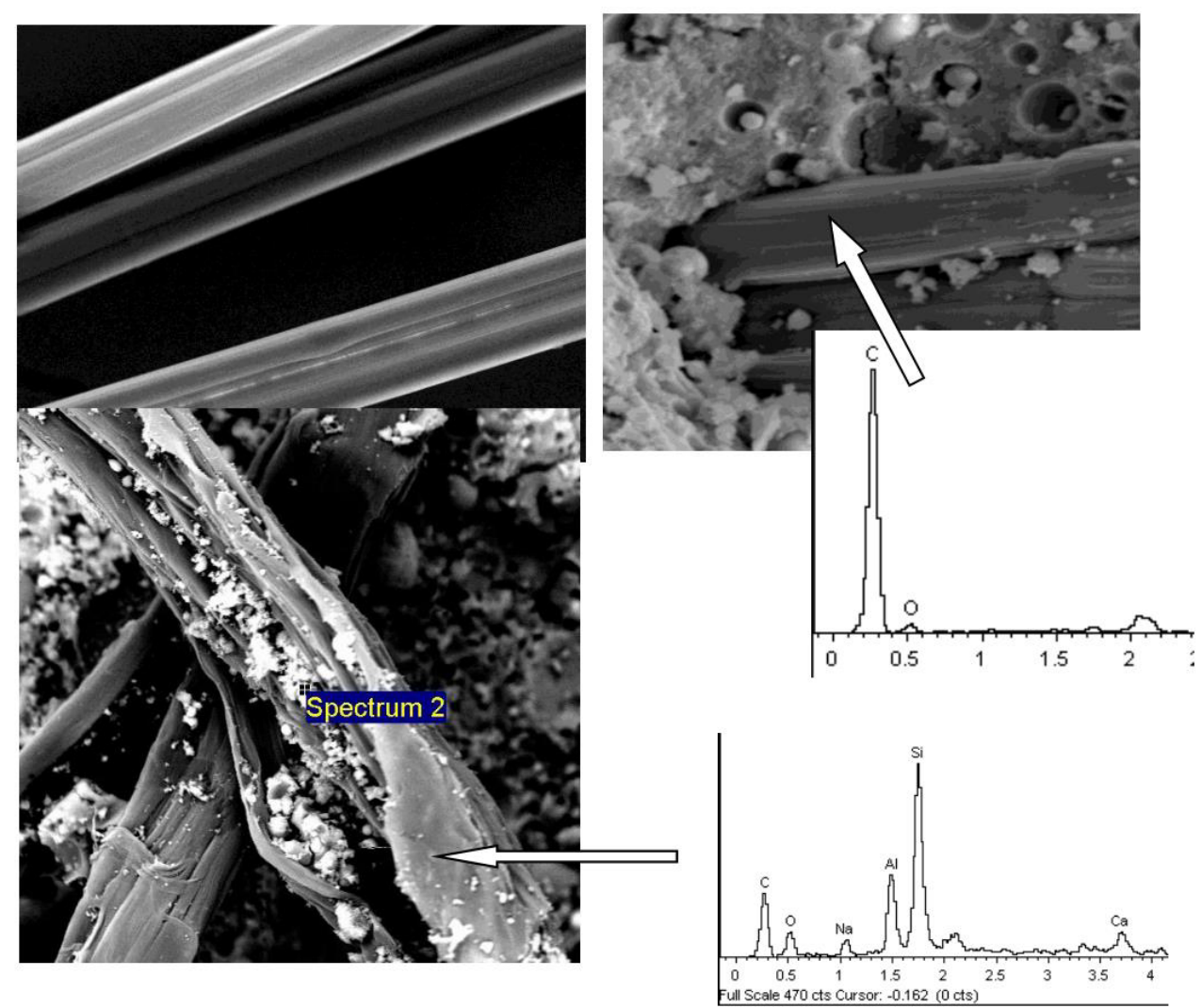

Fig. 3: SEM image of PE fibre surface as individual fibres (above-left) and no change of PE fibre surface in the geopolymer matrix (above-right and evidence of carbon peak for PE fibre in EDS insert). EDS showing the evidence of formation of geopolymer gel on the surface of PE fibres bundle (below-left) and EDS peaks in the insert.

\section{Conclusion}

Based on the limited variabilities of volume fractions of PE fibres and their effects on the tensile, flexure and compressive behavior of PE-FRGC, the following conclusions can be drawn:

- The compressive strength of the PE-FRGC decreases with increase in volume fractions of PE fibres due to formation of higher amount of entrapped air in the composite.

- The addition of PE fibres improves the ductility of PE-FRGC both in uni-axial tension and three-point bending. The PE fibre volume fraction of $1 \%$ is found to be the critical volume fraction for superior strain hardening and deflection hardening in uni-axial tension and three-point bending, respectively. 
- The uniform dispersion of PE fibres at $1 \%$ in the composite is believed to be the reason for such superior ductile behavior compared to higher fibre volume fractions.

- The examination of PE fibre surface through SEM and EDS analysis reveals no evidence of damage due to high alkalinity of geopolymer in the composite.

\section{References}

1. F.U.A. Shaikh, Mater. Des., 50, 674 (2013)

2. B. Nematollahi, J. Sanjayan, F.U.A. Shaikh, J. Mater. Civ. Eng., (2015)

3. B. Nematollahi, J. Sanjayan, F.U.A. Shaikh, Constr. Build. Mater., 70, 54 (2014)

4. S.F.U. Ahmed, M. Maalej, Constr. Build. Mater., 23(1), 96 (2009)

5. S.F.U. Ahmed, M. Maalej, P. Paramasivam, Constr. Build. Mater., 21(5), 1088 (2007)

6. Z. Zhang, Y. Xiao, H. Zhu, S. Hua, Y. Chen, J. Cent. South Univ. T., 16, 49 (2009) 